\title{
Fundamental movement skill and physical fitness measures in children with disabilities
}

\author{
Aija Klavina, Karina Ostrovska, and Martins Campa \\ Academy of Sport Education of Latvia, Riga, Latvia
}

\begin{abstract}
This study aimed to explore fundamental motor skills and physical fitness outcomes in the group of children with visual, physical and intellectual disabilities. Alongside the average data outcomes, possible gender differences in all measures were also explored. In addition, the association between the level of movement performance and physical fitness variables was investigated. Participants were 82 elementary school age children with mild to moderate disabilities (mean age 9.6 years). To assess fundamental movement skills (FMS), children completed the Test of Gross Motor Development (TGMD) -2. Physical fitness was measured by the four tasks including $30 \mathrm{~m}$ run, sit-ups, functional reach test, sit and reach test and handgrip strength. The average TGMD-2 score for the study group in locomotor skills corresponded to 6.3 years of age (39.3 points), while in object control skills it was at 6.6-7.6 years of age (30.9-36.3 points). The average scores in the fitness tests were $30.1 \mathrm{~cm}$ in the functional reach test, $17.1 \mathrm{~kg}$ in Handgrip test, 14.0 rep in Sit up test and $6.78 \mathrm{sec}$ in $30 \mathrm{~m}$ run. There were no significant differences in physical fitness tests results between boys and girls. The linear regression results presented that TGMD-2 skills significantly predicted $30 \mathrm{~m}$ run test $[\mathrm{F}(2 ; 161)=8.965, p=.000]$. Data analyses according to the level of movement performance and physical fitness showed significant associations between FMS outcomes and $30 \mathrm{~m}$ run test $(p<.05)$. The present study extended the small body of research on the fundamental motor skills of children with different functional limitations while having potential to participate in daily physical activities.
\end{abstract}

Keywords: children, disability, fundamental movement skills, physical fitness

\section{Introduction}

Physical activity participation is widely recognized as a critical component of health and development for children with and without disabilities (Ross, Case, \& Leung, 2016). However, obesity and physical inactivity among children and adolescents in our society has been increasing over the decades (Dairo, Collet, Dawes, \& Oskrochi, 2016; Milulevic et al., 2014). Lifelong participation in physical activity is a vital part of healthy lifestyle and also contributes development of physical skill competences for all children including those with physical, intellectual, sensory or other disabilities (Loprinzi, Davis, \& Fu, 2015; Majnemer, Shikako-Thomas, Schmitz, Shevell, \& Lach, 2015; Woodmansee, Hahne, Imms, \& Shields, 2016).

While research has significantly increased knowledge in the area of physical activity for children with disability during the last decade, there are still unknown and unexplored mechanisms of risk factors related to reduced physical activity in relation to secondary health issues (Raz-Silbiger et al., 2015; Rimmer, Chen \& Hsieh, 2011). Several authors have indicated that physical activity in childhood is believed to contribute to the development of healthy lifestyles in adulthood, preventing inactivity-related health problems (Koldoff \& Holtzclaw, 2015; Giagazoglou et al., 2013). For example, Li and colleagues (2016) indicated that children with cerebral palsy (CP) participated for $13 \%$ to $53 \%$ less in physical activities than peers with typical development. Furthermore, Capio and colleagues (2015) found that improvement of FMS in children with CP contributed to heightened daily physical activity level. In recent studies, researchers showed that persons with intellectual disability (ID) are physically inactive and more obese (Einarsson, Johannsson, Daly, \& Arngrimsson, 2016; Kreause, Ware, McPherson, Lennox, \& O'Callaghan, 2016). For example, Phillips and Holland (2011) found that none of 152 participants with ID met recommendations of daily physical activities. Moreover, for persons with Down syndrome the level of activity declined significantly with age. As reported by Cuesta-Vargas, Paz-Lourido and Rodriguez (2011) the physical fitness measurements such as strength, flexibility and balance are linked to the physical activity participation in people with ID. The low measurement outcomes relate to poor adherence to physical activity or/and sports programs. Also, children with visual impairments 
(VI) have lower daily physical activity performance in comparison with their sighted peers (Haibach, Wagner, \& Lieberman, 2014). The restricted participation is frequently related to a lack of knowledge of physical education professionals (Conroy, 2012; Holbrook, Caputo, Perry, Fuller, \& Morgan, 2009; Shapiro, Moffett, Lieberman, \& Dummer, 2005).

Fundamental movement competence is linked to physical activity in both children with and without disability (Barnett, Hinkley, Okely, \& Salmon, 2013). Recent research on physical activity participation among children with disability most frequently addressed the locomotor skills and object control skills, for example, the ability to jump, run, kick and throw efficiently in children with VI (Haibach et al., 2014; Wagner, Haibach, \& Lieberman, 2013), ID (Mache \& Todd, 2016; Westendrop, Houwen, Hartman, \& Visscher, 2011) and physical impairment (Loprinzi et al., 2015). Stodden et al. (2008) and Capio, Sit and Abernethy (2011) noted that locomotor and manipulative skills form the foundation for future movement and are considered essential for the development of more complicated or sport-specific motor skills. Moreover, Khodaverdi, Bahram, Khalaji and Kazemnejad (2013) presented locomotor and manipulative skills as indicators of physical skills mastery consequently enabling enjoyable participation in physical activities. Li et al. (2016) studied correlates of physical activity in children with physical disabilities and showed that physical and biological factors such as physical functioning ability and gross motor function were found to be consistently associated with PA, suggesting that increased physical and motor functioning is associated with higher levels of PA.

While much research supports gender differences in children without disability for FMS, for example, object control skills (e.g., Barnet, van Beurden, Morgan, Brooks \& Beard, 2010; Butterfield, Angel \& Mason, 2012), research on gross motor skills gender differences in the group of children with disabilities is relatively scarce. For example, Haibach et al. (2014) found no significant gender differences in locomotor skills for children with VI, while boys performed superior object control skills to girls. Different outcomes have been reported in research studies exploring gross motor skill performance regarding gender differences in children with learning disabilities. For example, Simons et al. (2008) found that boys had superior performance in ball skills to girls. Woodard and Surburg (1997) reported higher scores for boys on both locomotor skills and ball skills compared to girls. To our knowledge, no study has investigated gross motors performance and physical fitness skills regarding gender differences in the mixed group of children with various disabilities. There is also limited research on physical fitness skill gender differences in children with various disabilities. Much of such research has focused on exploring gender differences in children with ID (e.g., Frey \& Chow, 2006; Frey, Stanish, \& Temple, 2008), with only one known study examining fitness level in heterogynous group of children with functional limitations (Longmuir $\&$ Bar-Or, 2000).

Most frequently, components of physical activity in children with disabilities have been explored following the biomedical model according to the type and/or severity of disability. For example, processoriented and product-oriented measures in children with cerebral palsy (Capio et al., 2011), processoriented movement components for children with VI (Haibach et al., 2014), relationship between motor skills, participation in leisure activities and quality of life of children with developmental coordination disorder (Raz-Silbiger et al., 2015), the level of daily physical activity in children with autism (Pan, 2008), and in individuals with Down syndrome (Phillips $\&$ Holland, 2011). However, currently promoted inclusive model of education and sport services requires physical education teachers, sport instructors and adapted physical activity professionals deal with heterogeneous groups of children presenting different types and severity of functional restrictions. While biomedical model defines physical activity as body movements related to energy expenditure, the psychosocial model intends to look at physical activity as a measurable index of individualized health of the child reflecting his/her physical, social, and self-engagement outcome measures (Ross et al., 2016). According to a psychosocial model, restriction in physical activity can be caused by functional impairment (e.g., increased muscle tone) or social-environment factors (e.g., lack of physical activity services). The comprehensive understanding of a complex nature of physical activity in children with different disability would help selecting appropriate measurement instruments and discuss research outcomes in relation to multidimensional perspective to health status and daily activity experience.

The current research aimed to measure the fundamental motor skills (locomotor and manipulative) and physical functioning outcomes (strength, flexibility and balance) in heterogeneous group of elementary school children with different functional restrictions (intellectual, physical and VI). Alongside the average performance outcomes of the study group, this study 
explored possible gender differences in all measures. All participants were perceived as a group of individuals with common functional capacity for physical activity performance according to recommendations of the World Health Organization (WHO) [60 min moderate and vigorous physical activity (MVPA) per day] (World Health Organization, 2004). Methods were selected according to Ross and colleagues (2016) concept that allows for appropriate and comprehensive description of physical activity experiences of children with disabilities to link evaluation of FMS and physical fitness with the impact of disability within the context of daily living and child relevant life situations, such as organized and school-related sports, games and recreational play in the community.

\section{Methods}

\section{Participants}

Participants were 82 children (age 7-11 years) with mild and/or moderate physical, intellectual and visual disability (21 girls and 61 boys). Participants were selected from the national schools implementing special education programs classified by specific codes. Before applying to educational setting at age of 7 years, all children with disabilities in Latvia are assessed by the medical-pedagogical committee, including a neurologist, paediatrician, psychologist, special education teacher and other specialists as needed, recommending them special education programs. Children with mild to moderate ID are recommended for educational program with code 57 and 58 . Children with VI are recommended for educational program with code 51 that defines special education program for children with VI (Cabinet of Ministers of Latvia, 2008). Additional criteria were ability to follow verbal or visual instructions and ability to demonstrate locomotor and manipulative skills from the TGMD-2. All children could use their technical aids (e.g., glasses) during the study. Exclusion criteria included neurologic disease and other medical conditions that might influence participation in physical activities (e.g., severe ID, severe autism, seizures, diabetes, asthma, cardiopulmonary disease).

\section{Data Collection}

Participants were tested by licensed physiotherapists during the national sport event for children with disabilities. The study was approved by the Ethical Committee of the Latvian Academy of Sport Education and confirmed to the 1964 Helsinki Declaration.
All participants and/or their parents/guardians provided written consent prior to the study.

\section{Fundamental motor skill assessment}

The TGMD-2 (Ulrich, 2000) was used to obtain data on participants' fundamental motor skills. The TGMD-2 has been validated for children with VI (Houwen, Hartman, Jonker, \& Visscher, 2010), used in studies involving children with ID (Rintala \& Loovis, 2013; Zikl, Holoubková, Karásková, \& Veselíková, 2013) and physical disabilities (Capio et al., 2011). The TGMD-2 includes 6 locomotor skills (run, horizontal jump, slide, leap, hop and gallop) and 6 object control skills (two hand strike, catch, kick, overhand throw, stationary bounce and underhand roll). Each skill is evaluated based on performance criteria with score " 1 " if criterion was performed, or " 0 " if it was not performed. The TGMD-2 tasks were modified for children with VI according Lieberman and colleagues (2014). For example, sound box was used for locomotor skills, ball with bells inside for the catch and other audial modifications were applied if necessary. In a similar manner, according to Capio and colleagues (2011), for physical impairment, TGMD-2 tasks were modified for throwing and kicking, participants were instructed to use their dominant and also their unaffected side (e.g. hemiplegia). TGMD-2 tasks were performed twice by each participant. The maximum raw score for locomotor as well as for object control subtests was 48 points. The normative scores included the standardized score for the subtests, with mean and standard deviation. The interpretation of scores was done in percentiles where $50 \%$ was an average measure for children's overall gross motor ability. Scores lower than $50 \%$ showed the overall children motor ability below average and higher than $50 \%$ above average (Ulrich, 2000).

\section{Physical fitness assessment}

To evaluate physical skills modified parts of the Eurofit Test Battery (ETB) and Brockport physical fitness test battery were used. ETB has been validated to individuals with intellectual impairment and found to be a reliable instrument (Dobosz, Mayorga-Vega, \& Viciana, 2015; Donahoe, Turner, \& Worrell, 1994; Giagazoglou et al., 2013; McDonncha, Watson, \& McSweeney, 1999). Brockport physical fitness test battery is considered valid and reliable for ID (Boer \& Moss, 2016; Winnick \& Short, 2014), VI (Winnick $\&$ Short, 2014) and physical disabilities (Haga, 2008; Winnick \& Short, 2014). The following paragraphs 
describe subtests from the ETB and Brockport physical fitness test used in this study.

\section{Sit and reach test}

The Sit and reach test was performed in order to evaluate flexibility of children. The tests were administered using a wooden box of $30.5 \mathrm{~cm} \times 30.5 \mathrm{~cm}$ $\times 30.5 \mathrm{~cm}$ with a ruler at the top. Participants were sitting on the fitness mat with legs fully extended with feet placed flat against the measuring box (using $15 \mathrm{~cm}$ at the level of the feet). Both knees were fixed and pressed flat to the floor. The child reached forward along the measuring line as far as possible. The hands remained at the same level. All children made the attempt to reach out and hold the final position at least two seconds while the distance was recorded. The level of the feet was recorded as a zero, so that any measure that did not reach the toes was not recorded as a positive. The one practice and one trial was recorded to the nearest $\mathrm{cm}$.

\section{Handgrip test}

The Handgrip test was used to measure upper-body muscular maximum strength, precisely - strength of the hand and forearm muscles, as it has been correlated with upper extremity function (Cuesta-Vargas, 2011). Handgrip strength of the dominant hand was measured using an adjustable handgrip dynamometer (Saehan Sh5001 Hand Dynamometer, Korea). The child was instructed to maintain the standard bipedal position during the entire test with the arm in complete extension and not to touch any part of the body with the dynamometer except the hand being measured. The best result (in $\mathrm{kg}$ ) in two attempts was retained.

The Sit up test was used as a method to quantify abdominal muscle strength/endurance. The child lied in the supine position on a mat with his/her knees bent at 90 degrees and his/her feet flat on the floor held down by the examiner. The hands were crossed on the chest. After "Start" command, the student's elbows had to contact the knees and return to the starting position as many times as possible in $30 \mathrm{~s}$. The total number of repetitions completed in $30 \mathrm{~s}$ was retained.

\section{Functional reach test}

While several methods were revised on dynamic balance evaluation, the Functional reach test (FRT) was selected as a most suitable method for participants in this study. This test requires maintaining attention long enough while taking and holding the body position. It measures the maximal distance using a yardstick at the level of the acromion that an individual is able to reach forward from a starting standing position without losing balance or making the step. It has been reported to provide reliable measurements when used in children, both those developing typically and those with physical disabilities (Donahoe et al., 1994; Volkman, Stergiou, Stubger, Blanke, \& Stoner, 2009; Wong, Leung, Poon, Leung, \& Lau, 2013). FRT was measured using the same protocol as by Duncan, Weiner, Chandler and Studenski (1990). FRT was recorded as the difference between position 1 and 2 . The placement of the third metacarpal was recorded as position 1, while the child was standing in a relaxed stance with extended hand forwards. Position 2 was recorded after children were reaching as far forwards as they comfortably could and were holding the position for three seconds. Three trials were performed to determine average and taken for further analysis.

\section{Run test}

The Run test of $30 \mathrm{~m}$ was used to access the speed capabilities. The child started in a standing position. Participants ran across the designed area to a finish line. Two test trials were given and modifications advised by Winnick and Short (2014) for runners who are blind or with ID were used. For example, blind participants ran with assistant holding his/her elbow.

\section{Statistical analysis}

Statistical calculations were performed with SPSS 19.0. Descriptive statistics were used to calculate the mean age, anthropometric data, TGMD-2 scores and outcome of physical skill assessment. The multiple comparisons with the Bonferoni post-hoc test were used to determine differences by subgroup. The Spearmen's correlation coefficient $(p)$ was computed for each locomotor, object control measures and physical fitness. The correlations were interpreted as follows: $r<.20$, poor relationship; $0.21-0.40$, fair; $0.41-0.60$, moderate; $0.61-0.80$, good and $0.81-1.00$ values very good to excellent. Statistical significance was set at $p<.05$ for all tests. To examine whether the level of fundamental motor skills predicted physical fitness test outcomes, the multiple $R^{2}$ linear regression analyses were then performed using the total score of fundamental motor skills as predictors. Subsequently, to assess the relative importance of fundamental motor skills in predicting physical fitness test outcomes for participants, the standardized multiple regression coefficients were analyzed. 


\section{Results}

The mean age of participants was $9.6 \pm 1.6$ years (girls $9.2 \pm 1.6$ years, boys $9.8 \pm 1.5$ years). The average weight of the group was $38.3 \pm 10.4 \mathrm{~kg}$ and height $142.9 \pm 12.5 \mathrm{~cm}$ (Table 1).

Table 1

Descriptive characteristics of the sample

\begin{tabular}{lccc}
\hline & $\begin{array}{c}\text { Age } \\
(\text { years })\end{array}$ & $\begin{array}{c}\text { Height } \\
(\mathrm{cm})\end{array}$ & $\begin{array}{c}\text { Weight } \\
(\mathrm{kg})\end{array}$ \\
\hline Boys & $9.8 \pm 1.5$ & $144.0 \pm 12.8$ & $39.0 \pm 11.3$ \\
Girls & $9.2 \pm 1.6$ & $139.9 \pm 11.1$ & $36.2 \pm 6.8$ \\
Total & $9.6 \pm 1.6$ & $142.9 \pm 12.5$ & $38.3 \pm 10.4$ \\
\hline
\end{tabular}

\section{Results of Fundamental Motor Skills}

The average raw score for TGMD-2 locomotor subtest was $39.3 \pm 8.3$ points that correspond to the age of 6.3 years and is for 3.3 years lower than the mean chronological age of participants. The mean score for the object control subtests was $36.3 \pm 7.9$ points. For boys, the subtest mean score was $38.1 \pm 6.8$ points corresponding to the age of 6.6 years that is for 3.2 years lower than the mean chronological age. For girls, this score was $30.9 \pm 8.5$ points that correspond to age of 7.6 years and is lower for 1.6 years with regards to the mean of their chronological age. There were no significant differences in TGMD scores between boys and girls $(p>.05)$. Overall, in locomotor subtest, 41 participants scored under 50\% (30 boys and 11 girls) while in object control subtest, 51 participants scored under 50\% (39 boys and 12 girls) (Table 2).

\section{Results of Physical Fitness}

In Sit and reach test, 43 of 82 participants were able to reach at least minimum of the measurement scale while 39 participants could not perform minimum criteria of this task.

Because of limited successful attempts in this test, the Sit and reach results were not included in the further data analysis in this study.

In the functional reach test, the average score for the study group was $30.1 \pm 8.4 \mathrm{~cm}$. The mean result for girls was $31.9 \pm 10.1 \mathrm{~cm}$, while for boys $29.5 \pm 7.7 \mathrm{~cm}$ $(p>.05)$. The average result in the Handgrip test was $17.1 \pm 5.7 \mathrm{~kg}$. The mean result for girls was $15.8 \pm 5.4 \mathrm{~kg}$ while for boys it was $17.6 \pm 5.8 \mathrm{~kg}$ $(p>.05)$. Furthermore, the mean of the Sit up test was $14.0 \pm 8.7 \mathrm{rep}$ in $30 \mathrm{sec}$. The mean result for girls was $14.6 \pm 9.5$ times while for boys it was $15.0 \pm 8.6$ times $(p>.05)$. In $30 \mathrm{~m}$ run test, the mean result of the study group was $6.78 \pm 1.1 \mathrm{sec}$. The mean result for girls was $6.94 \pm 0.71 \mathrm{sec}$, while for boys it was $6.83 \pm 1.0 \mathrm{sec}$ $(p>.05)$. In this study, none of the tests outcomes had significant difference between boys and girls.

Table 2

Descriptive statistics of total TGMD-2 and physical fitness results

\begin{tabular}{lcccccc}
\hline & $\begin{array}{c}\text { Reach test } \\
(\mathrm{cm})\end{array}$ & $\begin{array}{c}\text { Handgrip } \\
(\mathrm{kg})\end{array}$ & $\begin{array}{c}\text { Sit up } \\
(\text { rep times })\end{array}$ & $\begin{array}{c}\text { Run } \\
(\mathrm{s})\end{array}$ & $\begin{array}{c}\text { Age equivalent } \\
\text { locomotor skills }\end{array}$ & $\begin{array}{c}\text { Age equivalent } \\
\text { object control skills }\end{array}$ \\
\hline $\begin{array}{l}\text { Boys } \\
(n=61)\end{array}$ & $29.5 \pm 7.7$ & $17.6 \pm 5.8$ & $15.0 \pm 8.6$ & $6.70 \pm 1.2$ & $39.8 \pm 8.8$ & $38.1 \pm 6.8$ \\
$\begin{array}{l}\text { Girls } \\
(n=21)\end{array}$ & $31.9 \pm 10.1$ & $15.8 \pm 5.4$ & $14.6 \pm 9.5$ & $7.03 \pm 1.0$ & $38.0 \pm 6.6$ & $30.9 \pm 8.5$ \\
Total & $30.1 \pm 8.4$ & $17.1 \pm 5.7$ & $14.0 \pm 8.7$ & $6.78 \pm 1.1$ & $39.3 \pm 8.3$ & $36.3 \pm 7.9$ \\
\hline
\end{tabular}

Table 3 presents the results of the multiple $\mathrm{R}^{2}$ linear regression analysis with fundamental motor skills predicting physical fitness test for participants. The regression model with the TGMD outcome skills as independent variables and fitness test as a dependent variable indicated that these skills significantly predicted only $30 \mathrm{~m}$ run test $[\mathrm{F}(2,161)=8.965, p=.000]$. These TGMD-2 skills explained $10 \%$ of variance in participants of this study. The results of standardized regression coefficients $(\beta)$ indicated that locomotor skills were significant contributors to predicting the outcome result in the $30 \mathrm{~m}$ run test, while object control skills did not display significant $\beta$ weights.

\section{Data analysis based on the performance of funda- mental motor skills}

In addition, this study explored whether the performance level of FMS was associated with physical fitness outcomes for children with disabilities. Based on the TGMD-2 scores, data of all participants were 
Table 3

Linear regression model examining the influence of level of fundamental motor skills on physical test outcome

\begin{tabular}{|c|c|c|c|c|c|c|c|}
\hline & $R^{2}$ & $\mathrm{~F}$ & $\mathrm{df}$ & $p$ & $B$ & $t$ & $p$ \\
\hline $\begin{array}{l}\text { Reach test } \\
\text { Model } \\
\text { Locomotor } \\
\text { Object control }\end{array}$ & .015 & 1.186 & 2,161 & $>.05$ & $\begin{array}{r}.150 \\
-.073 \\
\end{array}$ & $\begin{array}{r}1.524 \\
-.747 \\
\end{array}$ & $\begin{array}{l}>.05 \\
>.05 \\
\end{array}$ \\
\hline $\begin{array}{l}\text { Handgrip } \\
\text { Model } \\
\text { Locomotor } \\
\text { Object control }\end{array}$ & .015 & 1.198 & 2,161 & $>.05$ & $\begin{array}{l}.017 \\
.110\end{array}$ & $\begin{array}{r}.169 \\
1.124\end{array}$ & $\begin{array}{l}>.05 \\
>.05\end{array}$ \\
\hline $\begin{array}{l}\text { Sit-up } \\
\text { Model } \\
\text { Locomotor } \\
\text { Object control }\end{array}$ & .003 & .247 & 2,161 & $>.05$ & $\begin{array}{r}.065 \\
-.021 \\
\end{array}$ & $\begin{array}{r}.661 \\
-.211 \\
\end{array}$ & $\begin{array}{l}>.05 \\
>.05\end{array}$ \\
\hline $\begin{array}{l}30 \text { m run } \\
\text { Model } \\
\text { Locomotor } \\
\text { Object control }\end{array}$ & .100 & 8.965 & 2,161 & $<.05$ & $\begin{array}{l}-.222 \\
-.128\end{array}$ & $\begin{array}{l}-2.370 \\
-1.365\end{array}$ & $\begin{array}{l}<.05 \\
>.05\end{array}$ \\
\hline
\end{tabular}

Table 4

TGMD scores and physical fitness results divided according to the level of fundamental motor skill performance

\begin{tabular}{|c|c|c|c|c|c|}
\hline Sub- groups & $\begin{array}{c}\text { TGMD scores } \\
\text { divided }\end{array}$ & $\begin{array}{l}\text { Reach test } \\
\quad(\mathrm{cm})\end{array}$ & $\begin{array}{l}\text { Handgrip } \\
(\mathrm{kg})\end{array}$ & $\begin{array}{l}\text { Sit up } \\
\text { (rep) }\end{array}$ & $\begin{array}{l}\text { Run } \\
\text { (s) }\end{array}$ \\
\hline $\begin{array}{l}\operatorname{ApDev}_{\text {loc }} \\
(n=41)\end{array}$ & $44.0 \pm 2.7$ & $31.3 \pm 7.9$ & $17.5 \pm 5.1$ & $14 \pm 9.5$ & $6.12 \pm .47$ \\
\hline $\begin{array}{l}\operatorname{InDev}_{\text {loc }} \\
(n=41)\end{array}$ & $33.0 \pm 8.4$ & $28.9 \pm 8.8$ & $16.8 \pm 6.4$ & $15 \pm 8.1$ & $7.06 \pm .94$ \\
\hline $\begin{array}{l}\text { ApDev }_{\text {oc }} \\
(n=31)\end{array}$ & $41.0 \pm 5.1$ & $31.4 \pm 8.1$ & $16.2 \pm 5.2$ & $14 \pm 10.2$ & $6.59 \pm .80$ \\
\hline $\begin{array}{l}\mathrm{InDev}_{\text {oc }} \\
(n=51)\end{array}$ & $33.0 \pm 7.8$ & $29.3 \pm 8.5$ & $17.7 \pm 6.0$ & $15 \pm 7.8$ & $6.66 \pm .84$ \\
\hline
\end{tabular}

divided in four subgroups according to the level of fundamental motor skills performance (Table 4):

1. results of locomotor skills that were age appropriate were included in $\mathrm{ApDev}_{\text {loc }}$ data set $(\mathrm{n}=41)$;

2. results of locomotor scores under age appropriate scores were included in $\operatorname{InDev}_{\text {loc }}$ data set $(\mathrm{n}=41)$,

3. results of object control skills that were age appropriate were included in $\mathrm{ApDev}_{\mathrm{oc}}$ data set $(\mathrm{n}=31)$,

4. results of object control skills that were under age appropriate scores were included in $\operatorname{InDev}_{\mathrm{oc}}$ data set $(\mathrm{n}=51)$.

Furthermore, these four data subgroups were used to explore whether performance of fundamental motor skills was associated with physical fitness outcomes.
Because of limited number of results for girls and boys, the gender was not used for categorization of further data analyses. Table 5 presents correlation coefficient $(r)$ between the level of FMS and physical fitness results. The significant associations were found only between FMS outcomes and $30 \mathrm{~m}$ run test $(p<.05)$. The highest and strongest correlation was found between object skill outcomes and $\mathrm{InDev}_{\text {oc }}$ data subset $(-.750, \mathrm{p}<.001)$. Good correlation was found between locomotor skills of $\mathrm{ApDev}_{\mathrm{loc}}$ subset and $\mathrm{ApDev}$ oc subset (-.690 and -.713 , respectively, $p<.05)$.

\section{Discussion}

This study explored the fundamental motor skills and physical fitness in the heterogeneous group of children with different disabilities - physical, intellectual and 
Table 5

Correlation coefficients (r) between the level of fundamental motor skills and $30 \mathrm{~m}$ run test outcomes

\begin{tabular}{|c|c|}
\hline TGMD skills & $30 \mathrm{~m}$ run \\
\hline $\mathrm{ApDev}_{\text {loc }}$ & $-.690 *$ \\
\hline $\mathrm{InDev}_{\mathrm{loc}}$ & -.472 \\
\hline $\mathrm{ApDev}_{\mathrm{oc}}$ & $-.713 *$ \\
\hline $\mathrm{InDev}_{\mathrm{oc}}$ & $-.750 * *$ \\
\hline
\end{tabular}

VI. The focus was put on a group approach viewing all participants as being capable to perform relevant movement skills for participation in daily physical activities. According to Ross and colleagues (2016), health is a complex and dynamic construct and impact of disability on daily performance of the individual should be linked with an objective and subjective experience. The prior research studies have found that physical fitness and motor proficiency performance of children with disabilities are significantly lower than in children without disabilities (Einarsson, 2016; Farhat et al, 2015; Foley, Bryan, \& McCubbin, 2008; Wagner et al., 2013; Woodmansee et al., 2016; Capio, 2011; Capio, 2015), therefore, control group was not included in the data analyses.

In our study, $50 \%$ of participants $(n=41)$ scored under chronological age in locomotor skills, while $62 \%(\mathrm{n}=51)$ in object control skills. The average level of movement performance was corresponding to 6.3 years of age that was for 3.3 years lower than the mean age of the study group (9.6 \pm 1.6 years). Similarly, other authors have also found that children with functional impairments had lower gross motor skill scores compared to chronological age norms (Capio, Sit, Abernethy, \& Masters, 2012; Frey \& Chow 2006; Hartman, Houwen, \& Visscher, 2011; Zhang, 2001; Wagner et al., 2013). However, contrary to other studies (Barnett et al., 2013; Castelli \& Valley, 2007; Okely, Booth, \& Patterson, 2001), in this study, there were no significant differences in physical fitness and TGMD scores between boys and girls.

In this study, locomotor skills were significant predictors of $30 \mathrm{~m}$ running test results in elementary school age children with disabilities. These results were in line with previous studies demonstrating that manipulative skill proficiency was significantly associated with health-related physical fitness (Blair, Cheng, \& Holder, 2001; Haga, 2008). Furthermore, our results were partially in line with outcomes of other studies presenting associations between fundamental gross motor skills and physical activity levels (Capio, 2011; Lubans, Morgan, Cliff, Barnett, \& Okely, 2010). The ability to perform various FMS (for example, locomotor and object control skills) in a consistent and proficient manner is often defined as movement competence (Gallahue, Ozmun, \& Goodway, 2012). It is assumed, that children demonstrating higher movement competence have better physical activity performance and maintain enhanced fitness in later life (Barnett et al., 2013; Jaakkola, Yli-Piipari, Huotari, Watt, \& Liukkonen, 2015). Also, high levels of movement competence in childhood are related to a number of health and physical activity outcomes (Lubans et al., 2010).

In addition, similar to Capio and colleagues (2011) and Haga (2008), the correlation measure between the level of movement skills and physical fitness was explored. The significant correlation was found between $30 \mathrm{~m}$ running test outcomes and the level of FMS $\left(r_{\text {range }}=-.750\right.$ to $\left.-.690, p<.05\right)$ indicating that both age appropriate and also age inappropriate movement skill scores were associated with running performance. This outcome was contrary to other author statements that children with lower motor competence also have inferior physical fitness performance (Hands \& Larkin, 2006; Wrotniak, Epstein, Dorn, Jones, \& Kondilis, 2006). This might be explained by the fact that all children in our study were selected from special education settings providing physical education sessions at least 2 times per week for 40 to 45 minutes. While some children had lower qualitative performance of FMS (e.g., gallop, hoping, rolling or dribbling of the ball), they had sufficient movement experience to demonstrate quantitative characteristics of motor skills (e.g., intensity and/or amount of the movement performance). Many of participants were attending boarding schools, having environment (e.g., playgrounds, recess areas) that may also influence children's movement experience and intensity levels during school time (Ridgers, Salmon, Parrish, Stanley, \& Okely, 2012). Also, possible meaningful aspect of these outcomes could be psychoemotional nature. The data collection was done during the national sport event for children with disabilities providing participants attractive and positive atmosphere. Children tried to do all tasks as hard as possible and they were receiving positive feedback from physiotherapists, parents and teachers accompanying them during the event. According to King and colleagues (2010), children with low physical activity level do not necessarily demonstrate limited participation in physical activities with peers. 


\section{Limitations and Future Implications}

The movement skill measures and physical fitness tests applied in this study were selected according to the evidence of measurement instruments employed to groups of children with visual, physical and ID. Moreover, the inclusion criteria were that children are able to perform TGMD tasks independently while with little verbal or/and physical support (e.g., tactile cue to lift leg for children with VI). In such, the participation in the study was restricted by movement performance factor. According to the International Classification of Functionality (ICF) model, the activity should be linked with participation where participation, as is defined by the WHO, is the ability to engage in or the degree of involvement in meaningful life situations performance (World Health Organization, 2013). Future research should explore the association between the movement performance outcomes and activity and/or participation experiences of children with different types and level disabilities.

\section{Conclusions}

The present study extends the small body of research on the fundamental motor skills of children with different functional limitations while having potential to participate in daily physical activities. Future research should include larger sample of children with disabilities, giving more specific information on their performance. This study shows that elementary school-age children with mild disabilities in average perform under chronological age on gross motor skills. The significant relationship that was found between locomotor skills and running test supports the belief that higher levels of particular motor skills might contribute positively to children's physical activity performance.

\section{Acknowledgements}

This study was supported by the EEA/Norway Grants „Research and Scholarship" program in Latvia and done within the project „Health and Social Indicators of Participation in Physical Activities for Children with Disabilities" (NFI/R/2014/070).

\section{Declaration of Interest}

The authors report no conflict of interest. The authors alone are responsible for the content and writing of this article.

\section{References}

Barnett, L. M., van Beurden, E., Morgan, P. J., Brooks, L. O., \& Beard, J. R. (2009). Childhood motor skill proficiency as a predictor of adolescent physical activity. The Journal of Adolescent Health, 44, 252-259.

Barnett, L., Hinkley, T., Okely, A., \& Salmon, J. (2013). Child, family and environmental correlates of children's motor skill proficiency. Journal of Science and Medicine in Sport, 16(4), 332-336.

Blair, S. N., Cheng, Y. \& Holder, S. J. (2001). Is physical activity or physical fitness more important in defining health benefits? Medicine and Science in Sports and Exercise, 33, 379-399.

Boer, P., \& Moss, S. J. (2016). Effect of continuous aerobic vs. interval training on selected anthropometrical, physiological and functional parameters of adults with Down syndrome. Journal of Intellectual Disability Research, 60(4), 322-334.

Butterfield, S. A., Angell, R. M., \& Mason, C. A. (2012). Age and sex differences in object control skills by children ages 5 to 14. Perceptual Motor Skills, 114, 261-274.

Capio, C. M., Cindy, H. P. Sit, Eguia, K. F., Abernethy, B., \& Masters, R. S. W. (2015). Fundamental movemental movement skills training to promote physical activity in children with and without disability: A pilot study. Journal of Sports Health Science 4, 235-243.

Capio, C. M., Sit, S. H. P., \& Abernethy, B. (2011). Fundamental movement skills testing in children with cerebral palsy. Disability and Research, 33(25-26), 2519-2528.

Capio, C. M., Sit, C. H., Abernethy, B., \& Masters, R. S. (2012). Fundamental movement skills and physical activity among children with and without cerebral palsy. Research in Developmental Disability, 33,1235e41.

Castelli, D. M., \& Valley, J. A. (2007) The relationship of physical fitness and motor competency to physical activity. Journal of Teaching Physical Education, 26, 358-74.

Conroy, P. (2012). Supporting students with visual impairments in physical education. Insight: Research and Practice in Visual Impairment \& Blindness, 5(1), 3-10.

Cuesta-Vargas, A. I., Paz-Lourido, B., \& Rodriguez, A. (2011). Physical fitness profile in adults with intellectual disabilities: Differences between levels of sport practice. Research in Developmental Disabilities, 32, 788-794.

Dairo, Y. M., Collet, J., Dawes, H., \& Oskrochi, G. R. (2016). Physical activity levels in adults With intellectual disabilities: A systematic review. Preventive Medicine Reports, 4, 209-219.

Dobosz, J., Mayorga-Vega, D., \& Viciana, J. (2015). Percentile values of physical fitness levels among polish children aged 7 to 19 years - a population-based study. Cent Eur J Public Health, 23(4), 340-351.

Donahoe, B., Turner, D., \& Worrell, T. (1994). The use of functional reach as a measurement of balance in boys and girls without disabilities ages 5 to 15 years. Pediatric Physical Therapy, 6, 189-93.

Duncan, P. W., Weiner D. K., Chandler. J., \& Studenski. S., (1990). Functional Reach: A New Clinical Measure of Balance. Journal of Gerontology, 45(6), 192-197.

Einarsson, I., Johannsson, E., Daly, D., \& Arngrimsson, S. A. (2016). Physical activity during school and after school 
among youth with and without intellectual disability. Research in Developmental Disabilities, 56, 60-70.

Farhat, F., Hsairi, I., Baiti, H., Cairney, J., Mchirgui, R., \& Masmoudi K. (2015). Assessment of physical fitness and exercise tolerance in children with developmental coordination disorder. Research in Developmental Disabilities, 45-46, 210-219.

Foley, J., Bryan, R., \& McCubbin, J. (2008). Daily physical activity levels of elementary schoolaged children with and without mental retardation. Journal of Developmental \& Physical Disabilities, 20, 365-378.

Frey, G. C., \& Chow, B. (2006). Relationship between BMI, physical fitness, and motor skills in youth with mild intellectual disabilities. International Journal of Obesity, 30, 861-867.

Frey, G. C., Stanish, I. H., \& Temple, V. A. (2008) Physical activity of youth with intellectual disability: review and research agenda. Adapted Physical Activity Quarterly, 25(2), 95-117.

Gallahue, D. L., Ozmun, J. C., \& Goodway, J. (2012). Understanding motor development: Infants, children, adolescents, adults. New York: McGraw-Hill.

Giagazoglou, P., Kokaridas, D., Sidiropoulou, M., Patsiaouras, A., Karra, C., \& Neofotistou K. (2013). Effects of a trampoline exercise intervention on motor performance and balance ability of children with intellectual disabilities. Research in Developmental Disabilities, 34, 2701-2707.

Haga, M. (2008). Physical Fitness in children with movement difficulties. Physiotherapy, 94, 253-259.

Haibach, P. S., Wagner, M. O., \& Lieberman, L. J. (2014). Determinants of gross motor skill performance in children with visual impairments. Research in Development Disabilities, 35, 2577-2584.

Hands, B., \& Larkin, D. (2006). Physical fitness differences in children with and without motor learning difficulties. European Journal of Special Needs Education, 21, 447-456.

Hartman, E., Houwen, S., \& Visscher, C. (2011). Motor Skill Performance and Sports Participation in Deaf Elementary School Children. Adapted Physical Activity Quarterly, 28, 132-145.

Holbrook, E. A., Caputo, J. L., Perry, T. L., Fuller, D. K., \& Morgan, D. W. (2009). Physical Activity, Body Composition, and Perceived Quality of Life of Adults with Visual Impairments. Journal of Visual Impairment \& Blindness, 103(1), 17-29.

Houwen, S., Hartman, E., Jonker, L., \& Visscher, C. (2010). Reliability and validity of the TGMD-2 in primary-schoolage children with visual impairments. Adapted Physical Activity Quarterly, 27, 143-59.

Jaakkola, T., Yli-Piipari, S., Huotari, P., Watt, A., \& Liukkonen, J. (2015). Fundamental movement skills and physical fitness as predictors of physical activity: A 6-year follow-up study. Scandinavian Journal of Medicine \& Science in Sports, 26(1), 74-81. doi:10.1111/sms.12407

Khodaverdi, Z., Bahram, A., Khalaji, H., \& Kazemnejad, A. (2013). Motor skill competence and perceived motor competence: Which best predicts physical activity among girls? Iranian Journal of Public Health, 42, 1145-1150.

King, G., Petrenchik, T., Dewit, D., McDougall, J., Hurley, P., \& Law M. (2010). Out- of-school time activity participation profiles of children with physical disabilities: a cluster analysis. Child Care Health Development, 36(5), 726-41. doi: 10.1111/j.1365-2214.2010.01089.

Koldoff, E. A., \& Holtzclaw, B. J. (2015). Physical Activity Among adolescents with cerebral palsy:an integrative review. Journal of Pediatric Nursing, 30, e105-e117.

Kreause, S., Ware, R., McPherson, L., Lennox, N., \& O'Callaghan, M. (2016). Obesity in Adolescent with intellectual disability: Prevalence and associated characteristics. Obesity Research \& Clinical Practice, 10(5), 520-530.

Li, R., Sit, S. H. P., Yu, J. J., Duan, J. Z., Fan, C. M., \& Wong, S. H. S. (2016). Correlates of physical activity in children and adolescents with physical disabilities: A systematic review. Preventive Medicine 89, 184-193.

Lieberman L. J.,Haegele J. A., Columna L., \& Conroy P. (2014). How Students with Visual Impairments Can Learn Components of the Expanded Core Curriculum Through Physical Education. Journal of Visual Impairment \& Blindness, 108(3), 239-248.

Longmuir P. E., \& Bar-Or, O. (2000). Factors influencing the physical activity levels of youths with physical and sensory disabilities. Adapted Physical Activity Quarterly, 17, 40-53.

Loprinzi, P. D., Davis, R. E., \& Fu, Y. C. (2015). Early motor skill competence as a mediator of child and adult physical activity. Preventive Medicine Reports, 2, 833-838.

Lubans, D. R., Morgan, P. J., Cliff, D. P., Barnett, L. M., \& Okely A.D. (2010). Fundamental movement skills in children and adolescents: review of associated health benefits. Sport Medicine, 40(12), 1019-35.

McDonncha, C., Watson, A. W. S., \& McSweeney, T. D. J. (1999). Reliability of Eurofit Physical Fitness Items for Adolescent Males with and without Mental Retardation. Adapted Physical Activity Quarterly, 16(1), 86-95.

Mache, M. A., \& Todd, T. A. (2016). Gross motor skills are related to postural stability and age in children with autism spectrum disorder. Research in Autism Spectrum Disorders 23, 179-187.

Majnemer, A., Shikako-Thomas, K., Schmitz, N., Shevell, M., \& Lach L. (2015). Stability of leisure participation from school-age to adolescence in individuals with cerebral palsy. Research in Developmental Disabilities, 47, 73-79.

Milulevic, J., Vanhelts, J., Salleron, J., Marcellini, A., Comple, R., \& Bui-Xuan, G. (2014). Overweight in intellectualdisabled population: Physical, behavioral and phychological characteristics. Research in Development Disabilities 35, 153-161.

Okely, A. D., Booth, M. L., \& Patterson, W. (2001). Relationship of cardiorespiratory endurance of fundamental movement skill proficiency among adolescents. Pediatric Exercise Science, 13, 380-91.

Pan, C. J. (2008). School Time Physical Activity of Students With and Without Autism Spectrum Disorders During PE and Recess. Adapted Physical Activity Quarterly, 25, 308-321

Perkins, K., Columna, L., Lieberman, L., \& Bailey, J. (2013). Parents' perception of physical activity for their children with visual impairments. Journal of Visual Impairments \& Blindness, 107(2), 131-142.

Phillips, A. C., \& Holland, A. J. (2011). Assessment of Objectively Measured Physical Activity Levels in Individuals with Intellectual Disabilities with and without Down's 
Syndrome. PloS ONE, 6(12), e28618. doi:10.1371/journal. pone. 0028618

Raz-Silbiger, S., Lifshitz, N., Katz, N., Steinhart, S., Cermak, S. A., \& Weintraub, N. (2015). Relationship between motor skills, participation in leisure activities and quality of life of children with developmental coordination disorder: Temporal aspects. Research in Developmental Disabilities, 38, 171-180.

Ridgers, N. D., Salmon, J., Parrish, A. M., Stanley, R. M., \& Okely, A.D. (2012). Physical activity during school recess: a systematic review. American Journal of Preventive Medicine, 43(3), 320-328.

Rimmer, J. H., Chen, M. D, \& Hsieh, K. (2011). A conceptual model for identifying, preventing, and managing secondary conditions in people with disabilities. Physical Therapy, 91, $1728-1739$.

Rintala, P., \& Loovis, E. M. (2013). Measuring motor skills in Finnish children with intellectual disabilities. Perceptual and Motor Skills, 116(1), 294-303. doi:10.2466/25.10. pms.116.1.294-303

Ross, M. S., Bogart, R. K., Logan, S. W., Case, L., Fine, J., \& Thompson H. (2016). Physical Activity Participation of disabled children: A systematic review of conceptual and methodological approaches in health research. Frontiers in public health, 4, 187.

Ross, S. M., Case, L., \& Leung, W. (2016). Aligning Physical Activity Measures With the International Classification of Functioning, Disability and Health Framework for Childhood Disability. Quest, 68(4), 521-535. doi: 10.1080/00336297.2016.1145128

Shapiro, D., Moffett, A., Lieberman, L. J., \& Dummer, G. (2005). Perceived Competence of Children with Visual Impairments. Journal of Visual Impairment and Blindness, 99, 15-25.

Simons, J., Daly, D., Theodorou, F., Caron, C., Simons, J., \& Andoniadou, E. (2008). Validity and reliability of the TGMD-2 in 7-10 year old Flemish children with intellectual disability. Adapted Physical Activity Quarterly, 25, $71-82$.

Stodden, D. F., Goodway, J. D., Langendorfer, S., Roberton, M. A., Rudisill, M. E. \& Garcia, L. E. (2008). A developmental perspective on the role of motor skill competence in physical activity: An emergent relationship. Quest, 60, 290-306.

Ulrich, D. A. (2000). Test of gross motor development (2nd ed.). Austin, TX: PRO-ED.

Volkman K. G., Stergiou N., Stubger W., Blanke D., \& Stoner J., (2009). Factors Affecting Functional Reach Scores in Youth with Typical Development. Pediatric Physical Therapy, 21(1), 38-44.

Wagner, M.O., Haibach, P. S., \& Lieberman, L. J. (2013). Gross motor performance in children with and without visual impairments - Research to practice. Research in Development Disabilities, 34, 3246-3252.

Westendrop, W., Houwen, S., Hartman, E., \& Visscher, C. (2011). Are gross motor skills and sports participation related in children with intellectual disabilities? Research in Developmental Disabilities, 32, 1147-1153.

Winnick, J., \& Short, F. (2014). Brockport physical fitness test manual: A health-related assessment for students with disabilities. Champaign, IL: Human Kinetics.
Woodard. R. L., \& Surburg, P. R. (2001). The performance of fundamental movement skills by elementary school children with learning disabilities. The Physical Educator, 58, 198-206.

Wong, T. P. S., Leung, E. Y. W., Poon, C. Y. C., Leung, C. Y. F., \& Lau, B. P. H. (2013). Balance performance in children with unilateral and bilateral severe-to-profound grade. Hong Kong Physiotherapy Journal 31, 81-87.

Woodmansee, C., Hahne, A., Imms, C., \& Shields, N. (2016). Comparing participation in physical recreation activities between children with disability and children with typical development: A secondary analysis of matched data. Research in Developmental Disabilities, 49-50, 268-276.

World Health Organization (2013). How to use the ICF: A Practical Manual for using the International Classification of Functioning, Disability and Health (ICF). Exposure draft for comment. Geneva: WHO. Retrieved from: http://www. who.int/classifications/drafticfpracticalmanual2.pdf?ua=1

Wrotniak, B. H., Epstein, I. H., Dorn, J. M., Jones, K. E., \& Kondilis, V. A. (2006). The relationship between motor proficiency and physical activity in children. Pediatrics, 118, $1758-1765$.

Zhang, J. (2001). Fundamental motor skill performances of children with ADD, LD, and MMR- a pilot study. Palaestra, 7-9.

Zikl, P., Holoubková, N., Karásková, H., \& Veselíková, T. B. (2013). Gross Motor Skills of Children with Mild Intellectual Disabilities. International Journal of Social, Behavioral, Educational, Economic, Business and Industrial Engineering, 7(10), 2789-2795. doi:scholar.waset.org/1999.10/17209

\section{Corresponding author}

Aija Klavina

Email address | aija.klavina@gmail.com 